\title{
SISTEM INFORMASI PEMINJAMAN RUANG DAN BARANG DI UNIVERSITAS MURIA KUDUS BERBASIS WEB MENGGUNAKAN FITUR SMS NOTIFICATION
}

\author{
Ilham Khasbi \\ Fakultas Teknik, Program Studi Sistem Informasi \\ Universitas Muria Kudus \\ Email: ilhamkhasbi148@gmail.com \\ Fajar Nugraha \\ Fakultas Teknik, Program Studi Sistem Informasi \\ Universitas Muria Kudus \\ Email: Fajar.nugraha@umk.ac.id \\ Syafiul Muzid \\ Fakultas Teknik, Program Studi Sistem Informasi \\ Universitas Muria Kudus \\ Email: Syafiul.muzid@umk.ac.id
}

\begin{abstract}
ABSTRAK
Pendataan peminjaman ruang dan barang merupakan aktifitas yang penting sebagai sarana dokumentasi peminjaman di Universitas Muria Kudus. Proses peminjaman ruang dan barang di Universitas Muria Kudus dalam pelaksanaannya masih dilakukan secara manual dengan cara pihak peminjam datang ke BAU membawa surat permohonan peminjaman untuk melakukan transaksi peminjaman. Kemudian, dalam hal pencatatan item pinjaman juga masih dilakukan secara manual dengan cara petugas BAU menulis informasi peminjaman pada papan pengumuman. Dalam pelaksanaannya, terkadang petugas BAU lupa menulis informasi peminjaman pada papan pengumuman sehingga pihak BAU menerima lebih dari satu surat peminjaman dalam waktu dan tempat yang sama. Sistem Informasi Peminjaman Ruang dan Barang di Universitas Muria Kudus Berbasis WEB Menggunakan Fitur SMS Notification merupakan salah satu sistem yang dapat diterapkan di BAU. Sistem ini di buat untuk memperbaiki sistem manual yang telah ada menjadi terkomputerisasi sehingga bisa diakes melalui desktop maupun mobile serta dapat memberikan informasi peminjaman secara lengkap dan efisien yang disimpan dalam sebuah database server. Metode yang digunakan dalam pengembangan sistem ini menggunakan metode Waterfall, sedangkan untuk metode perancangan sistem menggunakan Unifed Modelling Language (UML). Hasil akhir penelitian ini berupa sistem peminjaman ruang dan barang di Universitas Muria Kudus yang berguna, lebih mudah, cepat dan terstruktur.
\end{abstract}

Kata kunci: sistem, informasi, peminjaman, SMS, waterfall.

\begin{abstract}
The documentation of reserving rooms and stuffs is important activity in the Universitas Muria Kudus. The process of resering rooms and stuffs in Universitas Muria Kudus in the real context still done manually, reserved side come to the Biro Administrasi Umum (BAU) and followed by application reserving letter for borrowing transaction. Then, in the process of registering the loan item also still has done manually. Officials write the information on the notice board in BAU. From statement above, the official BAU sometimes forgot to write the reserving information on the notice. So that, BAU side accepted more than one reserving letter in the same time and place. Web Based Information Systems Rooms and stuffs reservation in Universitas Muria Kudus by Using SMS Notification Feature is one system that can be applied in the BAU. The system is made to repair the exiting manual system to be computerized so it can be accesible through a desktop or mobile and may provide information more complete and efficient lending stored in a database server. The method used in the development of this system using the Waterfall method, while for the method of designing system using Unifed Modelling Language (UML). The result of this final research is a system that makes the room reservation and stuffs in Universitas Muria Kudus easier, faster, more structured, and usefull.
\end{abstract}

Keywords: system, information, reserving, SMS, waterfall. 


\section{PENDAHULUAN}

Perkembangan teknologi informasi saat ini sudah sangat cepat dan menjamur. Perkembangan teknologi informasi tidak akan berjalan dengan baik tanpa adanya dukungan sumber daya yang memadai. Dalam kehidupan sehari-haripun, manusia tidak terlepas dari teknologi informasi. Universitas merupakan salah satu lembaga yang sangat mengikuti perkembangan teknologi informasi, salah satunya pada proses pinjam meminjam barang atau aset.

Sistem peminjaman ruang dan barang di Universitas Muria Kudus dalam pelaksanaanya masih dilakukan secara manual. Proses peminjaman ruang dan barang di Universitas Muria Kudus selama ini dilakukan dengan cara pihak peminjam datang ke BAU untuk melihat informasi peminjaman yang ada pada kantor BAU. Setelah mengetahui informasi yang ada pihak peminjam membawa surat permohonan peminjaman yang di bawa ke bagian BAU kemudian diproses untuk penyetujuan. Kemudian untuk menandai ruang yang di pinjam, pihak BAU melakukan penulisan daftar peminjaman yang di tempelkan di papan informasi BAU. Dalam proses yang telah berjalan, terkadang pihak terkait lupa menulis daftar peminjaman ruang kemudian menerima surat permohoman peminjaman ruang pada hari yang sama namun berbeda peminjam sehingga terjadi tumpang tindih acara yang membuat salah satu pihak harus bersedia mengalah dan mengganti jadwal di ruang lain ataupun di hari yang lain.

Sehubungan dengan hal tersebut, maka dilakukan pengembangan sistem yang ada di BAU Universitas Muria Kudus dengan membuat sebuah aplikasi atau program untuk membantu dalam melakukan pengelolaan peminjaman secara online baik melalui desktop, smartphone ataupun tablet agar pihak internal kampus ataupun external kampus dapat lebih mudah untuk melakukan peminjaman ruang ataupun barang.

\section{METODOLOGI PENELITIAN}

\subsection{Metode Pengembangan Sistem}

Metode yang digunakan dalam pengembangan sistem menggunakan model waterfall. model waterfall sering juga disebut model sekuensial linier (squential linier) atau alur hidup klasik (classic life cycle). Model air terjun menyediakan pendekatan alur hidup perangkat lunak secara sekuensial atau terurut dimulai dari analisis, desain, pengodean, pengujian, dan tahap pendukung (support)[1]. Tahap-tahap dalam model waterfall, yaitu :

a. Analisis kebutuhan perangkat lunak merupakan proses pengumpulan kebutuhan secara intensif untuk menspesifikasikan kebutuhan perangkat lunak agar dipahami oleh user.

b. Desain adalah proses multilangkah yang fokus pada desain pembuatan program perangkat lunak termasuk struktur data, arsitektur perangkat lunak, representasi antarmuka dan prosedur pengkodean.

c. Pengkodean, desain diterjemahkan ke dalam program perangkat lunak.

d. Pengujian, proses yang dilakukan untuk meminimalisir kesalahan (error) dan memasukkan keluaran yang dihasilkan sesuai dengan keinginan.

e. Pemeliharaan, mengulangi proses pengembangan mulai dari analisis spesifikasi untuk perubahan perangkat lunak yang sudah ada, tapi tidak untuk membuat perangkat lunak baru.

\subsection{Metode Perancangan Sistem}

Dalam melakukan perancangan sistem diperlukan pemodelan untuk menggambarkan proses-proses perpindahan data dari proses satu ke proses yang lain. Metode yang digunakan dalam perancangan sistem ini menggunakan metode pemodelan Unifield Modeling Language (UML). UML merupakan standarisasi bahasa pemodelan untuk pembangunan perangkat lunak yang dibangun dengan menggunakan teknik pemrograman berorientasi objek. UML muncul karena adanya kebutuhan pemodelan visual untuk menspesifikasikan, menggambarkan, membangun, dan dokumentasi dari sistem perangkat lunak. UML merupakan bahasa visual untuk pemodelan dan komunikasi mengenai sebuah sistem dengan menggunakan diagram dan teks-teks pendukung. UML hanya berfungsi untuk melakukan pemodelan, penggunaan UML tidak terbatas pada metodologi tertentu [1].

\subsection{Metode Pengumpulan Data}

Untuk mendapatkan data yang benar-benar akurat, maka dilakukan pengumpulan sumber data dengan cara: 


\subsubsection{Sumber Data Primer}

Data yang diperoleh secara langsung dari obyek penelitian baik melalui pengamatan, pencatatan terhadap obyek penelitian yang meliputi:

a. Observasi

Merupakan teknik pengumpulan data yang dilakukan melalui pengamatan terhadap suatu objek penelitian secara langsung. Observasi dilakukan untuk memperoleh informasi yang terjadi secara nyata. Data yang didapat dari metode ini adalah data tentang proses peminjamana ruang dan barang Universitas Muria Kudus.

b. Interview (wawancara)

Pengumpulan data melalui tatap muka dan tanya jawab langsung dengan sumber data atau pihakpihak yang berkepentingan yang berhubungan dengan penelitian. Pada metode ini peneliti mengadakan wawancara langsung dengan karyawan BAU untuk memperoleh data yang di perlukan untuk penelitian serta menggali informasi tentang prosedur peminjaman ruang dan barang di Universitas Muria Kudus.

\subsubsection{Sumber Data Sekunder}

Data yang diambil secara tidak langsung dari objek penelitian. Data ini diperoleh dari buku-buku, dan literatur-literatur yang meliputi:

a. Study Kepustakaan

Pengumpulan data dari buku-buku yang sesuai dengan tema permasalahan. Misalnya, pengumpulan teori-teori mengenai perancangan sistem informasi peminjaman untuk penyusunan laporan. Dengan menggunakan studi pustaka maka penyusun mendapatkan data yang lebih akurat dan dapat dipertanggungjawabkan.

b. Studi Dokumentasi

Pengumpulan data dari literatur-literatur dan dokumentasi dari internet, diktat, atau sumber informasi lain yang sesuai dengan materi sistem informasi peminjaman.

\subsection{Penelitian Terkait}

Adapun penelitian yang telah dipublikasikan dalam jurnal berkaitan dengan sistem informasi peminjaman diantaranya :

a. Perancangan Sistem Informasi Peminjaman Buku Pada Perpustakaan SMK Negeri Kebonagung oleh Windha Fransiska Yopie dan Asis Ahmadi menghasilkan sistem informasi peminjaman yang pengelolaannya dilakukan secara terkomputerisasi. Penelitian ini menggunakan bahasa pemrograman PHP dan perancangan sistem menggunakan DFD [2].

b. Sistem Informasi Pengelolaan Data Peminjaman Barang Praktek Jurusan TIK Pada SMK Bhina Tunas Bhakti Berbasis Web oleh Nur Setyo Asih menghasilkan sistem informasi peminjaman yang menggunakan bahasa pemrograman PHP dengan perancangan sistem UML [3].

c. Sistem Informasi Monitoring Inventori Barang Pada Balai Riset Standarisasi Industri Bandar Lampung oleh Arie Setya Putra dan Ochi Marshella Febriani menghasilkan sistem informasi peminjaman barang berbasis desktop dan perancangan sistem menggunakan DFD [4].

d. Perancangan Sistem Informasi Peminjaman Buku Dan Komik Pada Taman Bacaan Fortune Baleharjo Pacitan oleh Ika Purnamasari menghasilkan sistem informasi peminjaman buku dan komik dengan menggunakan bahasa pemrograman PHP dan berfungsi agar data-data tersimpan dengan rapi dan memberikan manfaat bagi karyawan dalam melakukan pencatatan transaksi penyewaan buku, sehingga tidak terjadi kesalahan [5].

e. Penerapan Sistem Inventory Labotarium Digital Dengan Metode Critical Succes Factor Pada Perguruan Tinggi Raharja oleh Khanna Tiara, dkk menghasilkan sistem informasi inventaris laboratoriun digital dengan menggunakan bahasa pemrograman PHP dan berfungsi memudahkan Perguruan Tinggi Raharja untuk monitoring pengumpulan data barang, monitoring peminjaman barang dan pembuatan laporan di dalam Lab. Digital [6].

f. Perancangan Sistem Informasi Inventaris Program Studi Teknik Informatika Universitas Surakarta Oleh Ayu Prawiyanti, dkk menghasilkan sistem informasi inventaris dengan menggunakan bahasa pemrograman PHP dan perancangan system menggunakan DFD [7]. 


\section{HASIL DAN PEMBAHASAN}

\subsection{Analisa Kebutuhan Data dan Informasi}

Sistem Informasi Peminjaman Ruang dan Barang di Universitas Muria Kudus Berbasis Web menggunkan fitur SMS Notification tidak akan bisa beroperasi tanpa adanya data yang valid serta informasi yang mendukung. Adapun kebutuhan data dan informasi yang dibutuhkan diantaranya:

a. Data yang dibutuhkan dalam penelitian ini diantaranya : data user, data permohonan, data ruang, data barang, data mobil, dan data sopir.

b. Kebutuhan informasi yang diperlukan dalam penelitian ini adalah : Informasi peminjaman ruang dan barang, Informasi jadwal peminjaman, Informasi persetujuan peminjaman, dan Informasi laporan peminjaman.

\subsection{Use Case Diagram}

Merupakan pemodelan untuk kelakuan (behavior) sistem informasi yang akan dibuat. Berikut ini adalah sistem usecase peminjaman ruang dan barang yang di gambarkan pada Gambar 1 .

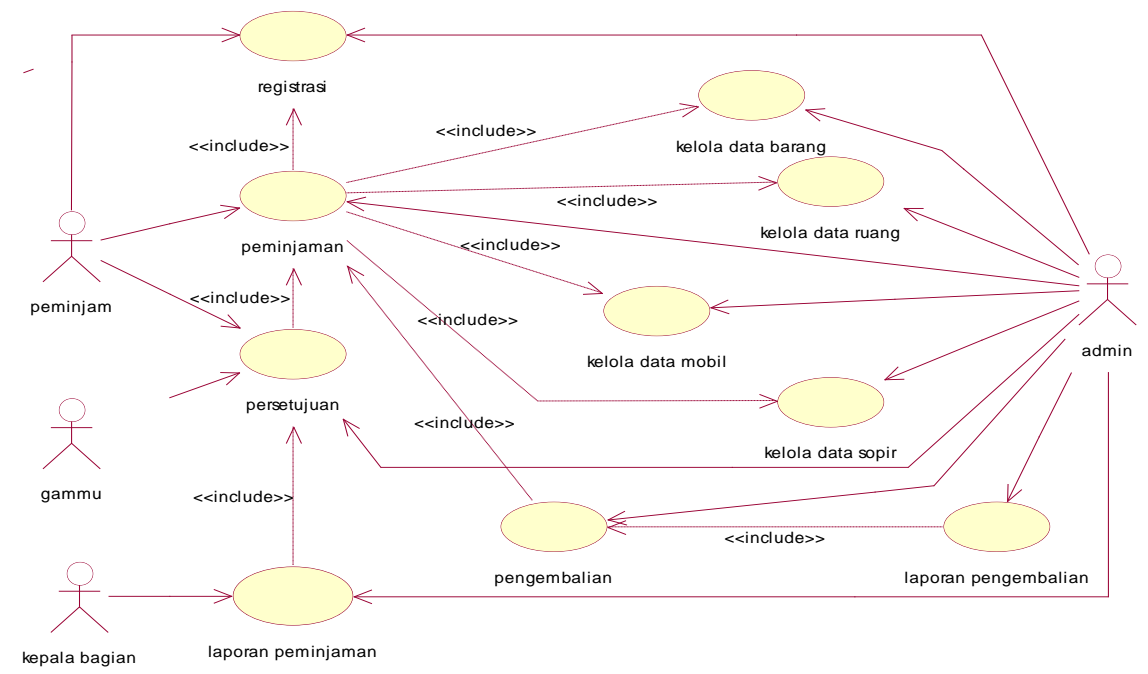

Gambar 2. Use case Diagram Sistem Peminjaman Ruang Dan Barang

\subsection{Class Diagram}

Menggambarkan struktur sistem dari segi pendefinisian kelas-kelas yang akan dibuat untuk membangun sistem. Adapun class diagram peminjaman ruang dan barang dapat dilihat pada Gambar 2.

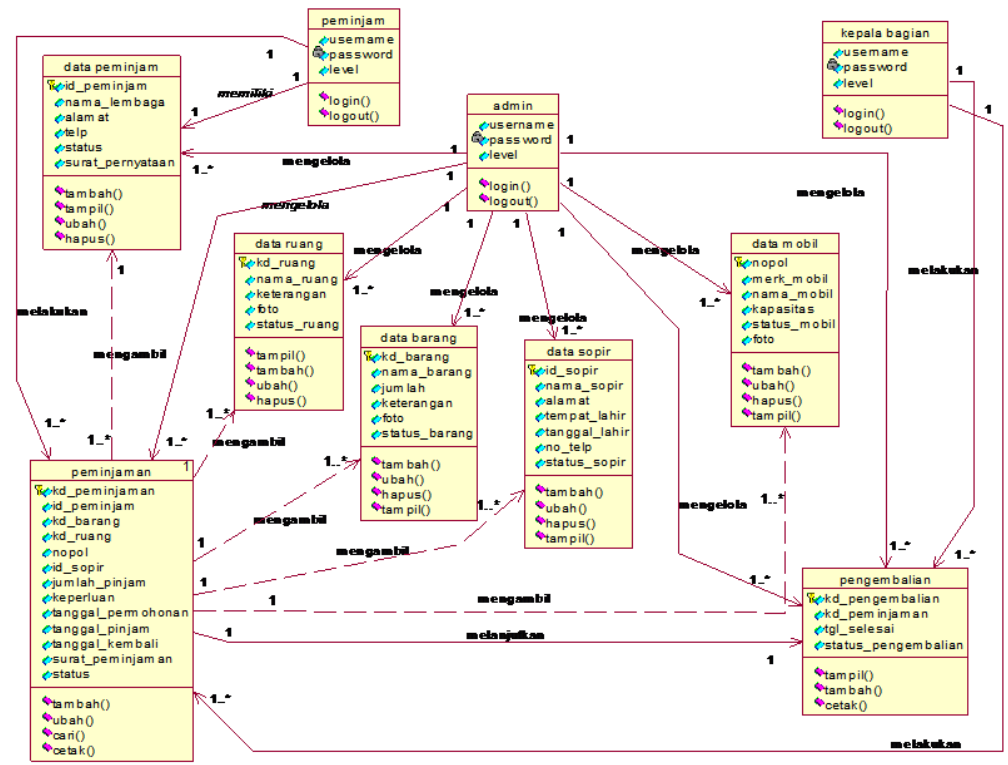

Gambar 3. Class Diagram Sistem Peminjaman Ruang Dan Barang 


\subsection{Perancangan Basis Data}

Suatu sistem informasi tidak akan berjalan tanpa adanya basis data (database). Adapun stuktur database yang terbentuk dalam sistem informasi peminjaman ruang dan barang di Universitas Muria Kudus dapat dilihat pada Gambar 3.

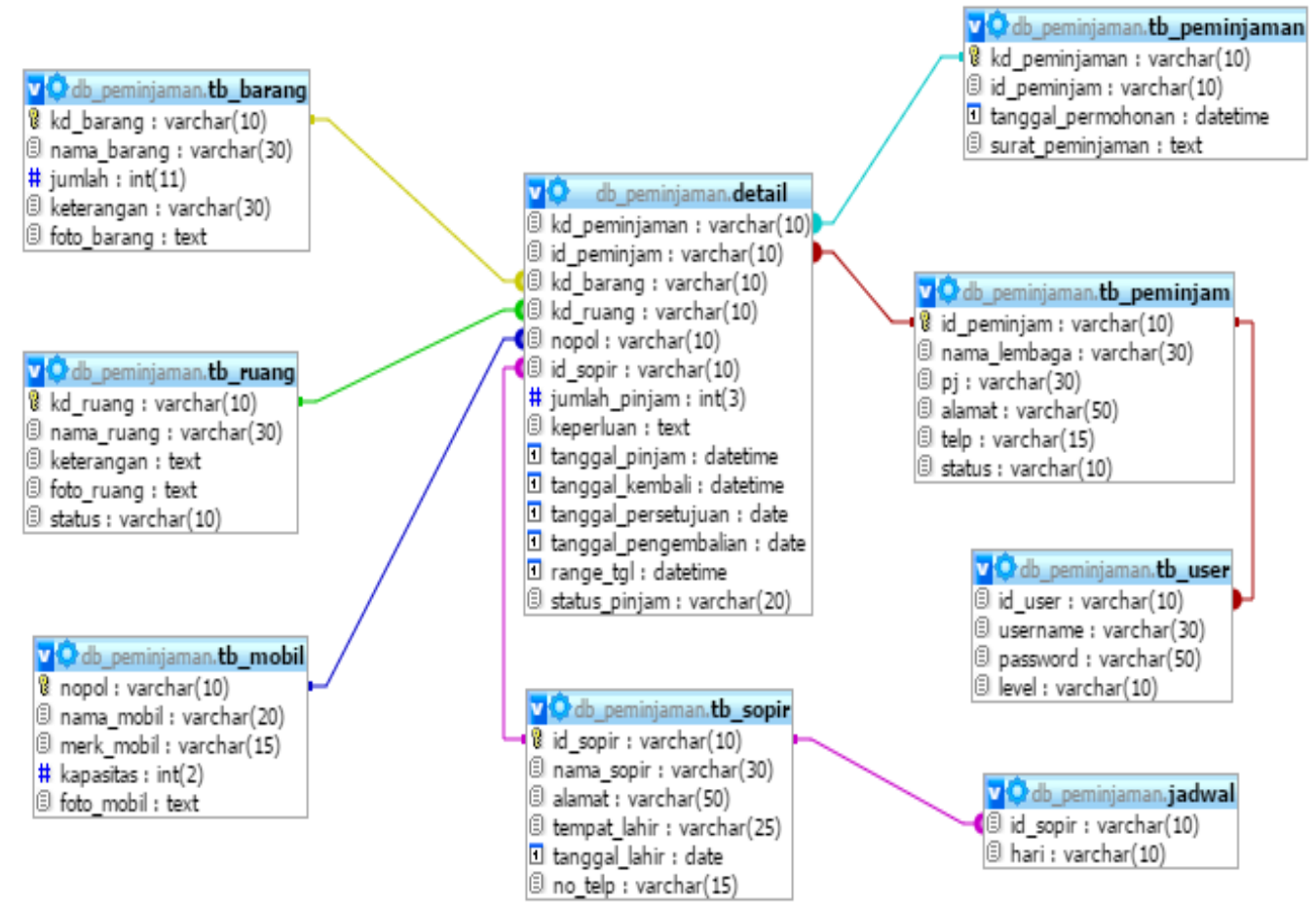

Gambar 4. Relasi Tabel

\subsection{Implementasi Sistem}

Implementasi adalah tahapan penerapan dan pengujian sistem. Implementasi merupakan salah satu tahapan dalam pengembangan sistem perangkat lunak. Pada tahap ini akan dilakukan implementasi hasil perancangan ke dalam baris-baris kode program yang dapat dimengerti oleh computer. Halaman utama merupakan halaman awal pada sistem yang pertama kali muncul ketika sistem dijalankan. Adapun tampilan halaman utama sistem dapat dilihat pada Gambar 4.

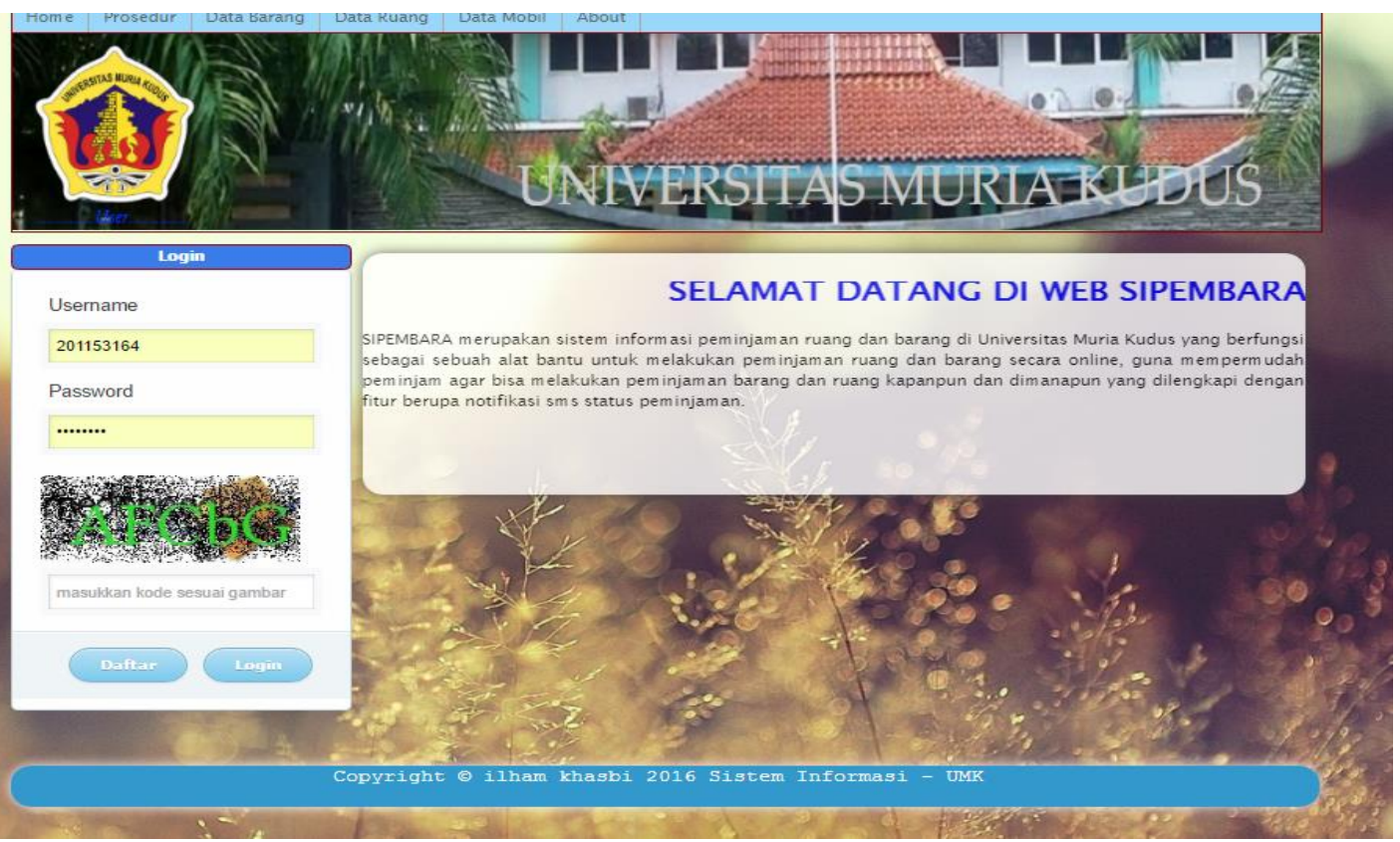

Gambar 5. Halaman Utama Sistem 
Halaman peminjaman ditampilkan ketika user peminjam sudah melakukan login sistem. Agar dapat melakukan peminjaman, user harus memilih jenis pinjaman terlebih dahulu dilanjutkan dengan memasukkan data tanggal pinjam dan tanggal kembali kemudian ditekan cari untuk melihat data yang tersedia pada tanggal yang di inginkan. Adapun form peminjaman dapat dilihat pada Gambar 5.

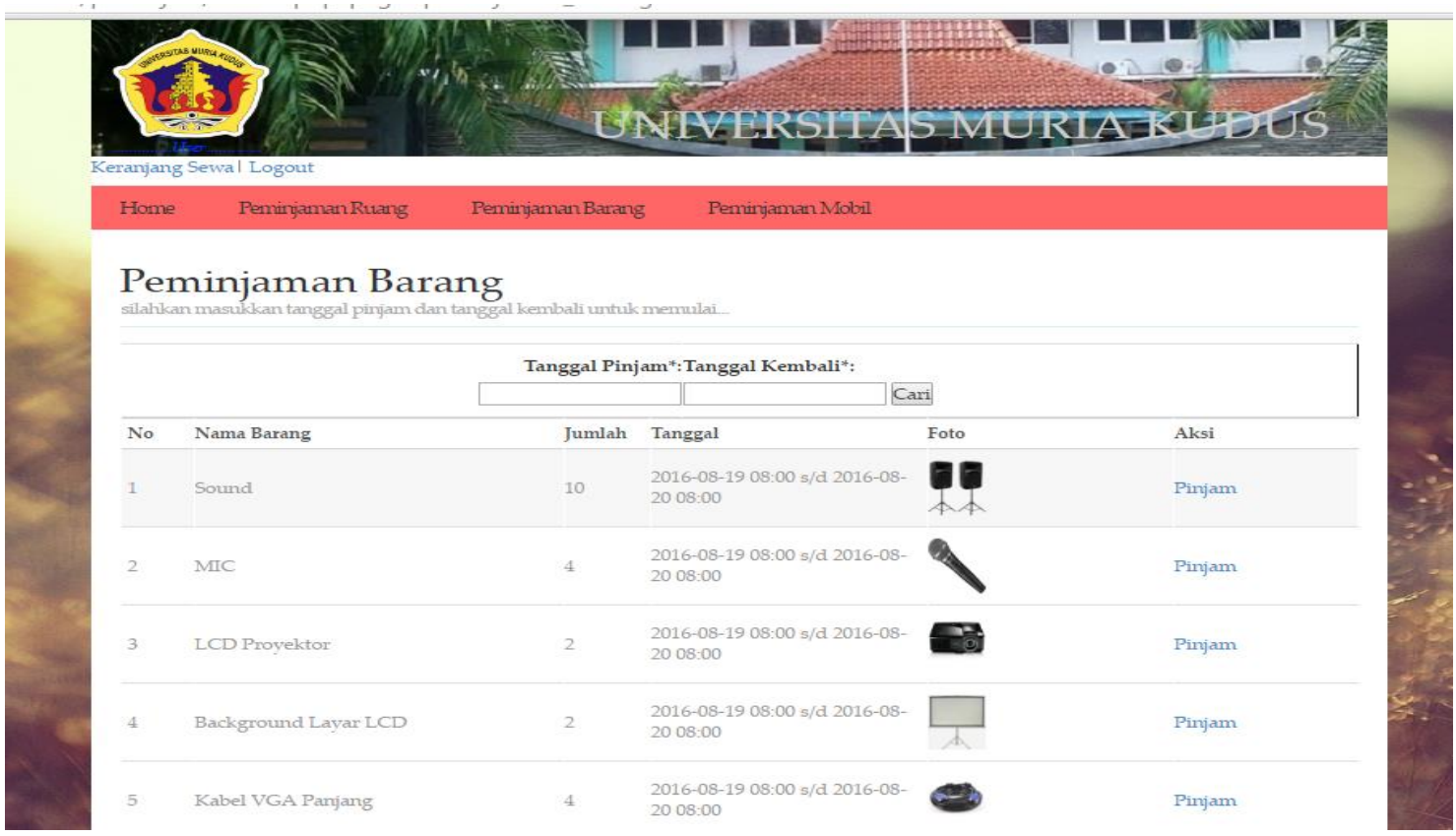

Gambar 6. Halaman Peminjaman

Halaman verifikasi ini tersedia pada menu admin untuk menampung semua data peminjaman dari user yang belum di verifikasi. Untuk melakukan verifikasi, admin dapat melihat detail pinjaman berupa surat yang telah diupload oleh user dilanjutkan menentukan aksi persetujuan atau penolakan. Pada aksi ini user nantinya menerima informasi status peminjaman berupa sms secara otomatis. Adapun tampilan halaman verifikasi dapat dilihat pada Gambar 6.

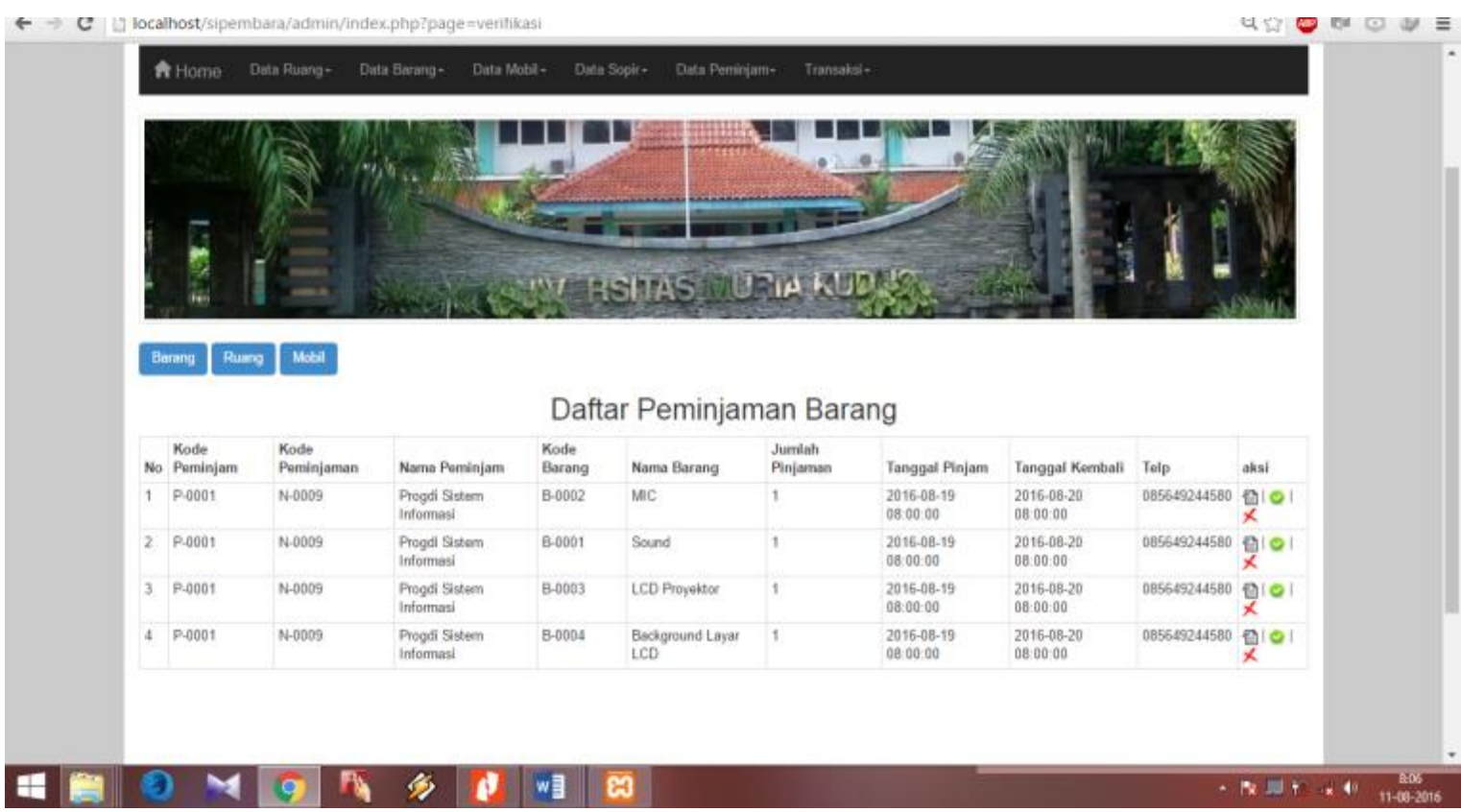

Gambar 7. Halaman Verifikasi 
Halaman laporan peminjaman ini tersedia pada hak akses menu kepala bagian. Laporan peminjaman tersedia secara periodik dalam kurun waktu bulanan. Adapun tampilan laporan peminjaman dapat dilihat pada Gambar 7.

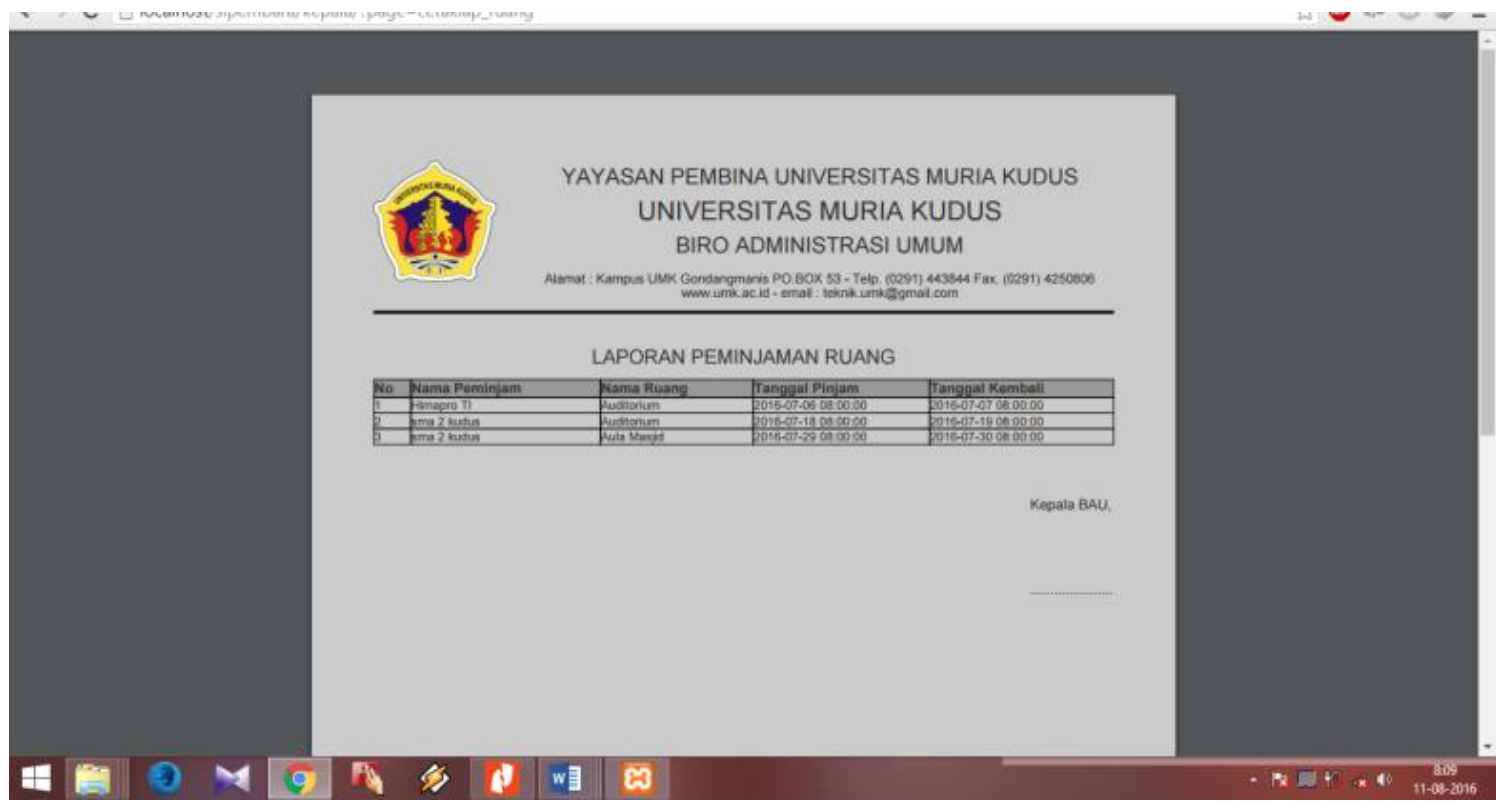

Gambar 8. Laporan Peminjaman

\section{KESIMPULAN}

Berdasarkan hasil perancangan dan pembuatan sistem informasi peminjaman ruang dan barang di Universitas Muria Kudus berbasis web menggunakan fitur SMS Notification dapat diperoleh kesimpulan bahwa :

1) Aplikasi yang dibuat menghasilkan sistem informasi peminjaman ruang dan barang berbasis web yang responsif diberbagai ukuran layar dengan tampilan yang menarik.

2) Aplikasi peminjaman yang dibuat mencakup peminjaman ruang, peminjaman barang, serta peminjaman mobil.

3) Aplikasi peminjaman ini memiliki dua tipe aktor peminjam, yaitu peminjam internal yang dapat meminjam keseluruhan item dan peminjam external yang hanya mampu meminjam ruang tertentu.

4) Sistem ini memiliki kemampuan untuk mengirimkan pesan status peminjaman berupa sms.

5) Aplikasi yang dibuat mampu menghasilkan laporan peminjaman serta pengembalian secara periodik dalam bentuk pdf.

\section{DAFTAR PUSTAKA}

[1] Sukamto, R. A., dan Salahuddin, M. (2011). Modul Pembelajaran Rekayasa Perangka Lunak Trstruktur dan Berientasi Objek, Bandung: Modula.

[2] Yopie, W. F., dan Ahmadi, A. 2015. "Perancangan Sistem Informasi Peminjaman Buku Pada Perpustakaan SMK Negeri Kebonagung”. IJNS. 4. 3, 8-12.

[3] Asih N.S., 2013, Sistem Informasi Pengelolaan Data Peminjaman Barang Praktek Jurusan TIK Pada SMK Bhina Tunas Bhakti Berbasis Web. Skripsi.

[4] Putra, A. S., 2013. "Sistem Informasi Monitoring Inventori Barang Pada Balai Riset Standarisasi Industri Bandar Lampung”. Jurnal Informatika. 13. 1, 90-98.

[5] Purnamasari, I. 2013. "Perancangan Sistem Informasi Peminjaman Buku Dan Komik Pada Taman Bacaan Fortune Baleharjo Pacitan”. Indonesian Jurnal on Computer Science. 10. 3, 2088-0154.

[6] Tiara, K, D. Immaniar, dan F. Arzia., 2015. "Penerapan Sistem Inventory Labotarium Digital Dengan Metode Critical Succes Factor Pada Perguruan Tinggi Raharja Industri Bandar Lampung”. Jurnal Informatika. 9. 1, 1978-8282. 
[7] Prawiyanti, A. A, Triyono, R. A., 2013. "Perancangan Sistem Informasi Inventaris Program Studi Teknik Informatika Universitas Surakarta". Seminar Riset Unggulan National Informatika dan Komputer. 2. 1, 2302-1136 